\title{
The challenge of embedding an ecosystem services approach: patterns of knowledge utilisation in public policy appraisal
}

\author{
John Turnpenny \\ School of Political, Social and International Studies, University of East Anglia, \\ Norwich NR4 7TJ, England; email: j.turnpenny@uea.ac.uk \\ Duncan Russel \\ Department of Politics, Amory Building, University of Exeter, Exeter EX4 4RJ, England; \\ email: d.j.russel@exeter.ac.uk
}

\author{
Andrew Jordan \\ Tyndall Centre, School of Environmental Sciences, University of East Anglia, \\ Norwich NR4 7TJ, England; email: a.jordan@uea.ac.uk \\ Received 18 January 2013; in revised form 31 July 2013
}

\begin{abstract}
The 'ecosystem services approach' (ESA) to policy making has refocused attention on how knowledge is embedded in policy. Appraisal has long been identified as an important venue for embedding, but suffers from well-known difficulties. This paper examines the extent to which an ESA appears in UK policy appraisal documents, and how far implementing an ESA via appraisal may encounter the same difficulties. A clear understanding of this is vital for interrogating claims that improving knowledge necessarily leads to more sustainable ecosystem management. The paper reports on the content of seventy-five national-level policy appraisals undertaken in the United Kingdom between 2008 and 2012. Only some elements of an ESA appear, with even the environment ministry failing to systematically pick up the concept, which is indeed subject to many of the familiar barriers to embedding environmental knowledge in appraisals. Policy initiatives attempting to institutionalise ecosystem values need to be conversant with these barriers.
\end{abstract}

Keywords: ecosystem services, policy appraisal, UK, public policy, knowledge utilisation

\section{Introduction}

The global Millennium Ecosystem Assessment (MEA, 2003), which raised the international profile of the ecosystem services approach (ESA) (see Jordan and Russel, 2014), is based on the premise that managing ecosystems sustainably requires sufficient good knowledge about how they function to be embedded in decision-making processes. The United Kingdom was one of the first countries to formally respond to this challenge with the publication of its National Ecosystem Assessment (NEA) in 2011 (UK NEA, 2011a; Waylen and Young, 2014). The NEA built upon the work undertaken in the MEA, and arguably represents the most comprehensive overview to date of the state of the natural environment in a nationstate. The NEA was also firmly underpinned by the argument that an audit of the services provided by ecosystems would give the basis for embedding environmental knowledge in decision making. Crucially, the NEA argued that the capacity of UK natural resources to deliver ecosystem services had declined dramatically over the last sixty years. This decline was, in large part, attributed to the fact that the natural world, and its constituent ecosystems, "are consistently undervalued in conventional economic analyses and decision making" (UK NEA, 2011b, page 5). 
However, the 'problem' of undervaluation was not presented as arising from too little knowledge per se. Far from it: "we already have sufficient understanding to manage our ecosystems more sustainably and good evidence of the social benefits that would arise from doing so" (page 14). Rather, the problem was presented as being one of knowledge production and embedding. But environmental knowledge is embedded within policy making in certain contexts; witness the large growth in environmental regulation across the EU in the past thirty years (Haigh, 2008), much of it premised on scientific knowledge of problems, thresholds, and potential solutions. Thus, the NEA's invocation requires more detailed investigation around a set of more specific questions, such as how, by whom, and in what contexts is knowledge about ecosystems - and the services they provide — already embedded in policy making? Moreover, why are the observed patterns as they are? This may lead to a better understanding of the barriers and enablers to more extensive embedding. This is the premise of this paper, which examines the extent to which ecosystems knowledge, particularly the ESA, is embedded within the practices of policy appraisal. A clear understanding of this, and the reasons for the observed patterns, is vitally important for interrogating the claim that improving knowledge will necessarily lead to more sustainable ecosystem management.

The paper unfolds as follows. In section 2 we introduce the ESA, the venue of policy appraisal, and the literature on the ways that appraisal has operated, particularly how different sorts of knowledge are embedded within it. From the gaps thus observed are derived a set of research questions. In section 3 we outline a methodology for studying these empirically. In section 4 we summarise the findings of an empirical assessment of the degree of embedding in a representative sample of UK policy-level appraisals conducted between 2008 and 2012; that is, before and after the publication of the NEA. In section 5 we analyse these results in the light of the research questions, before outlining the policy implications of the findings and pinpointing some important areas for future research in section 6.

\section{Exploring the use of knowledge about ecosystems in appraisals}

We define ESA in the spirit of that promoted by the MEA, the NEA, the UK's Natural Environment White Paper, and supplementary guidance in the Treasury's Green Book. Specifically, an ESA is taken to cover: supporting services, such as soil formation, nutrient and water cycling; regulating services, such as pollination and regulation of pests and diseases, and the way the climate and water systems work; provisioning services, such as provision of food, fibre, fuel, water; and cultural services, such as gardens, parks, lakes, wilderness, leisure, education, and aesthetic aspects (UK NEA, 2011b, page 18). Evidence of other aspects central to an ESA include: consideration of indirect and long-term impacts; integration between environmental, social, and economic aspects of ecosystems; and use of analytical tools around capturing values of different ecosystems, often in monetary terms. The focus is hence widened beyond a narrow framing of the ESA into broader references to ecosystems and other environmental concerns more generally.

The MEA clearly shows how ecosystems knowledge assessment fits within iterative decision-making analytical processes (eg, MEA, 2003, chapter 8). But there are many different contexts or venues in which the embedding of knowledge about ecosystems into policy could in principle occur [for a review of these so-called 'response options' see chapter 27 of the UK NEA (2011a)]. These include expert advisory bodies, legislative inquiries, and planning systems (see, for example, Barker, 1993; Cowell and Lennon, 2014; Howlett and Craft, 2012; Russel et al, 2013). Policy appraisal is one of the principal venues promoted by both environmental economists (eg, see Hanley, 2001; Pearce 1998; 2004; Turner, 2007) and political systems such as the European Union (CEC, 2009; 2012) and the UK (HM Treasury, 2012). Appraisal is, of course, not the only venue (Jordan and Schout, 2006), but it is widely identified as being a particularly promising one in which to embed an ESA in policy making. 
However, appraisal is rather "different" (Radaelli, 2007, page 3) from other venues. In many venues, knowledge is assumed to flow from knowledge generators into the decisionmaking processes. Getting knowledge utilised is thus heavily determined by the ability of 'generators' to find the right moment to 'deploy' their knowledge. With appraisal, on the other hand, it is the policy maker that is supposed to search for and weigh the knowledge for himself or herself. Indeed, in many jurisdictions appraisal is mandatory; there is an obligation on policy makers - many of whom are generalists rather than specialists with analytical skillsto collect and show, via published reports, that they have collated and utilised knowledge in their policy-making activities. Of course, the act of performing appraisal does not mean that a particular type of knowledge will be used (Hertin et al, 2009; Nilsson et al, 2008; Turnpenny et al, 2008). Nonetheless, given the widespread diffusion of policy appraisal techniques across the world in the last ten to twenty years (Radaelli, 2005), this is a particularly important venue in which to observe how far an ESA might be employed (see Jordan and Russel, 2014).

The UK provides an excellent case in which to examine the embedding of knowledge about ecosystems in policy making. Since the late 1980s, policy appraisal has played a particularly important role in UK environmental policy making; in fact, the UK is often said to be a 'front runner' in the development and application of appraisal (Russel and Jordan, 2007; Russel and Turnpenny, 2009). The 1990 Environment White Paper (DoE, 1990) rolled out a system of ex ante appraisal to assess the environmental impacts of major policy developments regardless of sector, acknowledging the fact that many of the activities causing environmental degradation reside in nonenvironmental policy sectors (eg, transport, energy). That system was originally dominated by economic thinking, with guidance (DoE, 1991) strongly advocating a cost-benefit approach with monetary quantification of impacts. In 2004 it was replaced by a more integrated form of 'regulatory impact assessment' (RIA), in which potential environmental impacts of policy options were assessed alongside other impacts such as the regulatory burdens on business, race, health, and gender. In 2007 RIA was rebranded as impact assessment (IA), and responsibility for its oversight moved from the Cabinet Office to the Department for Business, Enterprise and Regulatory Reform (now Business, Innovation and Skills). IAs are generally required for all government interventions of a regulatory nature, whether primary and secondary legislation, as well as codes of practice or guidance.

The UK was also, as noted above, one of the first countries to respond to the MEA. Crucially, the 2011 Natural Environment White Paper (HM Government, 2011), which in part sought to implement the findings of the UK NEA, strongly emphasised the importance of appraisal for embedding ecosystems knowledge into policy. This was backed up by supplementary guidance to the Treasury's Green Book (HM Treasury, 2012), the 'bible' on appraisal. And, although the monetary valuation of ecosystems and the environment is not uncontroversial (see, eg, Foster, 1997; Haines-Young and Potschin, 2009; Norgaard, 2010), the strong economic framing of an ESA in the UK (see Waylen and Young, 2014) has arguably made it especially amenable to utilisation within quantitative rational appraisal techniques such as cost-benefit analysis (see Hockley, 2014). In the UK such techniques have been promoted for at least the last thirty years (see, eg, review by Turner et al, 2003). So, overall, the UK is a highly appropriate place to examine the extent of ecosystem knowledge embedding in policy-level appraisal.

But while the NEA (eg, UK NEA, 2011a, chapter 27) showed that appraisal is a venue in which knowledge about ecosystems can be used, it did not systematically examine how far this had actually been achieved in the past. The NEA's statement that the UK's natural environment has been undervalued in UK policy making suggests policy appraisal has been less than successful as an integration mechanism. Indeed, there is a growing body 
of literature - not cited in the NEA - that suggests the implementation of policy appraisal has been somewhat at odds with the economically framed 'textbook' model of how it should work [see Adelle et al (2012) for a comprehensive review; and Hertin et al (2009), Nilsson et al (2008), Russel and Jordan (2007; 2009), Russel and Turnpenny (2009), and Turnpenny et al (2009), among many others]. This research has generated a fairly consistent picture of the empirical 'reality' of appraisal, including that: the economic aspects of policy all too easily crowd out other issues (eg, social and environmental) in appraisal processes (eg, Hertin et al, 2009; Russel and Turnpenny, 2009; Wilkinson et al, 2004); appraisals tend to be performed at a relatively late stage in the policy process and consequently have little or no influence over the final decisions made (Hertin et al, 2009; Russel and Jordan, 2009; Russel and Turnpenny, 2009); and more advanced appraisal tools such as computer modelling are rarely used despite the amount of investment in them (Nilsson et al, 2008). Many different reasons for these observations are identified. These include the educational background of government staff or their professional identity (eg, Dunlop and Russel, 2012); and lack of resources (time, money, and human) (see, for example, Russel and Jordan, 2007; Turnpenny et al, 2009), resulting in preferential use of the most readily available (rather than necessarily the most useful) data. Such accounts generally focus on the microlevel of individual actions and decisions regarding appraisal (Turnpenny et al, 2008). They are based on the premise that producing and embedding a strong knowledge base for appraisal is a resource-intensive activity, whereas policy makers are often faced with resource constraints (Russel and Jordan, 2007; Turnpenny et al, 2008). This can be compounded by the fact that policy makers often do not have the required analytical skills or knowledge to conduct a comprehensive appraisal.

The policy appraisal literature - and the associated policy recommendations - has often tended to concentrate on these microlevel factors enabling or constraining knowledge use. However, it is also important to look beyond these microscale enablers and constraints (Billé et al, 2012) to those at more mesoscales and macroscales. Craik et al (2012, page 20) note that the operation of assessment "depends on the political and institutional characteristics within which it is embedded", and argue for the relevance of informal 'norms' about how policy gets made. The role of appraisal as a tool of political power distribution - and also as a tool influenced by political power-is critical (page 33).

At the mesolevel (Turnpenny et al, 2008) several factors influence the way in which knowledge is collected and deployed in appraisal. These include the political, organisational, and institutional traditions of ministries - particularly, the function of analysis within the institutions, informal 'norms' about how policy gets made, and core strategic beliefs and priorities impacting upon what the remit of the appraisal is, and hence what gets assessed (Craik et al, 2012; Hertin et al, 2009); departmental competition among ministries leading to some issues in departments being prioritised over others to promote a department's cause within government (Russel and Jordan, 2007; 2009); the strength or otherwise of appraisal quality-control mechanisms (Dunlop et al, 2012); and the degree of path dependence on earlier policy decisions (Turnpenny et al, 2008).

There are also macrolevel enablers and constraints. These include the political desire to maintain flexibility and control over policy decisions and to especially avoid politically inconvenient results in the appraisal analysis (Russel and Turnpenny, 2009; Turnpenny et al, 2008). Moreover, critics argue that appraisal is far from value neutral; it has embedded discourses which can empower some actors and agendas over others (Craik et al, 2012, page 33; Owens et al, 2004) and is conversely malleable enough to be hijacked by specific political agendas (Dunlop et al, 2012). Finally, decisions made elsewhere, such as EU law and international agreements, mean that, frequently, policy appraisal processes become rather 
peripheral exercises because the agenda has already been largely set (eg, Russel and Jordan, 2007).

Acknowledging these mesolevel and macrolevel influences leads us towards a parallel related area of literature unexplored by the NEA, concerning the uses to which knowledge about ecosystems are put in decision making (see Dunlop, 2014). Echoing the classic typology of Weiss (1979), in the area of ecosystem services, Billé et al (2012) identified several different 'modes' of use of ecosystem valuation being applied in different decisionmaking venues: instrumental both ex ante and ex post, conceptual or enlightenment, and justificatory. Instrumental use relates to direct use in facilitating a specific decision, whereas a justificatory deployment of valuation is perfunctory as policy makers seek to justify a predetermined policy or demonstrate that they have gone through a bureaucratic procedure (Russel and Jordan, 2007). Conceptual use occurs where the accumulation of knowledge gradually contributes to long-term 'enlightenment' (Owens, 2012, page 8).

In sum, though there is a growing literature around ESA, and extensive literature on appraisal, there is very little which investigates how these concepts may interact. This paper proposes two main research questions based on the above literature:

(1) To what extent does the ESA appear in UK policy appraisal documents? Because of the variety of instrumental, justificatory, and conceptual ways that knowledge is deployed, it might be expected only to see gradual evidence of diffusion and embedding of concepts such as an ESA in the relatively short period around and since the NEA. Furthermore, given the UK's long history of environmental appraisal, it might be expected that more general environmental impacts of policy are more likely to appear in the sample than specific references to the (relatively new) conceptual terminology associated with an ESA (eg, see Russel and Jordan, 2007; Russel and Turnpenny, 2009).

(2) What issues surround ESA's embedding (or not) in policy appraisal? It might be expected that implementing an ESA within appraisal systems is not exempt from the difficulties, outlined above, in embedding any form of environmental knowledge into appraisal (eg, Coleby et al, 2012).

\section{Methods}

Measuring influence of an idea or concept is difficult when going beyond a simple inputoutput model (Rich, 1997, page 16), and a variety of methods are required for full analysis. For example, in Rich's typology of ways that knowledge may be used, detecting 'use' and 'utility' are likely to require in-depth surveys and case studies over extended periods of time. Similarly, understanding some of the more subtle modes of use (symbolic, strategic, coproduction) and the role of boundary work (eg, Owens, 2012), arguably demands detailed process tracing. As a first-step analysis, this paper concentrates on document analysis to assess how ecosystems and ecosystem services appear in a sample of UK IAs, rather than extensively examining the influences of an ESA on policy outputs and longer term outcomes. This approach is extremely useful because policy makers are required to use appraisal documents to record in a transparent manner the different sources drawn upon in assessing the potential impacts of different policy options. Documentary analysis allows us to map patterns of knowledge use over time with the degree of consistency a written record offers. Indeed, an appraisal report represents a discrete event, a snapshot of evidence around a policy area at a particular time, as well as a summary of a knowledge-gathering and marshalling process, and hence contains clues to the different influences on the final results.

We examined the content of seventy-five IAs conducted in the UK between 2008 and 2012 (see summary table A1 in the appendix). This period represents the progressive embedding of ESA within UK policy discourse, its explicit framing within the UK NEA and Natural Environment White Paper in summer 2011, and eighteen months beyond that. The sample 
contained fifteen IAs from each year, chosen to achieve roughly equal proportions of IAs covering (i) environmental policies; (ii) policies related to environment-principally those with potentially significant environmental impacts (agriculture, housing and land, energy and natural resources, transport); and (iii) nonenvironmental policies (eg, social security, sport, criminal law). Within each of those broad categories, the IAs were sampled at random. As an indication, an average total of 335 IAs per year were carried out between 2008 and 2011 (this fell significantly to just forty-two IAs in 2012). Some IAs were deemed to cover two or more policy fields; in these cases, if one or more of the policy fields was deemed environment or environment related, the whole IA was classed as environment related. The sample was coded by two of the authors. To ensure reliability, a subsample was assessed by both coders to ensure consistency; frequent consultation between coders sought to minimise intercoder variability. The final totals were: seventeen environment cases, thirty-six environmentrelated cases, and twenty-two nonenvironment cases. The departments which initiated the IA were also recorded to see how far an ESA had, as the NEA envisages, spread beyond its 'home domain'; that is, the environment ministry - the Department for Environment, Food and Rural Affairs (Defra) - its strongest advocate in the UK government.

To classify the degree of embedding of environmental considerations or ESA in appraisals, this paper builds on Helming et al (2013) in distinguishing between the extent to which policy is framed around an ESA (for environment and environment-related policies) and the extent to which potential impacts of the policies are assessed from an ESA perspective (all policies). For both 'framing' and 'impacts', the seventy-five IAs were classified on the following criteria:

- Type 0: no ecological or environmental knowledge referred to.

- Type 1: environment mentioned but not evaluated at all.

- Type 2: the environment mentioned but some elements are missing, and those that are there are only weakly evaluated.

- Type 3: strong environment framing and evaluation, but ecosystems not explicitly mentioned.

- Type 4: contains framing around an ESA but does not carry out much analysis; in this sense it identifies the ecological impact of the proposed policy but does not analyse beyond vague descriptions. In-depth analysis of the different services affected is lacking.

- Type 5: an ESA fully embedded throughout; that is, as well as explicitly referring to one or more of the ecosystem services, the IA examines long-term impacts; considers indirect impacts; takes an integrative approach (both between policy fields and environment, social and economic aspects); and uses different valuation tools - or other types of analytical tools such as monetary assessment, modelling, foresight exercises, or participatory tools to understand ecosystem complexity.

The IAs were also assessed for the degree of consideration of cultural, provisioning, regulating, and supporting services, to gain a more nuanced insight into how ecological knowledge is understood and covered in appraisals. Note that higher type numbers are not necessarily 'better' than lower numbers. For example, an appraisal classed as type 3 may have a large number of ESA-type elements in it, but just not explicitly framed in those terms. Conversely, an IA may readily employ the terminology of ESA but analyse only the constituent elements (ie, services) to a more limited extent. Finally, the typology is not normative - there is no judgment as to whether embedding an ESA is a 'good' thing; rather, it simply assesses the degree to which the concept appears in the way that policy options are described and compared in the appraisal documents. 


\section{Patterns of knowledge utilisation in the venue of policy appraisal}

In this section we present the empirical findings, while in section 5 we analyse the key findings in light of the expectations in section 2. Figure 1 shows the percentage of appraisals in the sample that conformed to each of the six different types set out above.

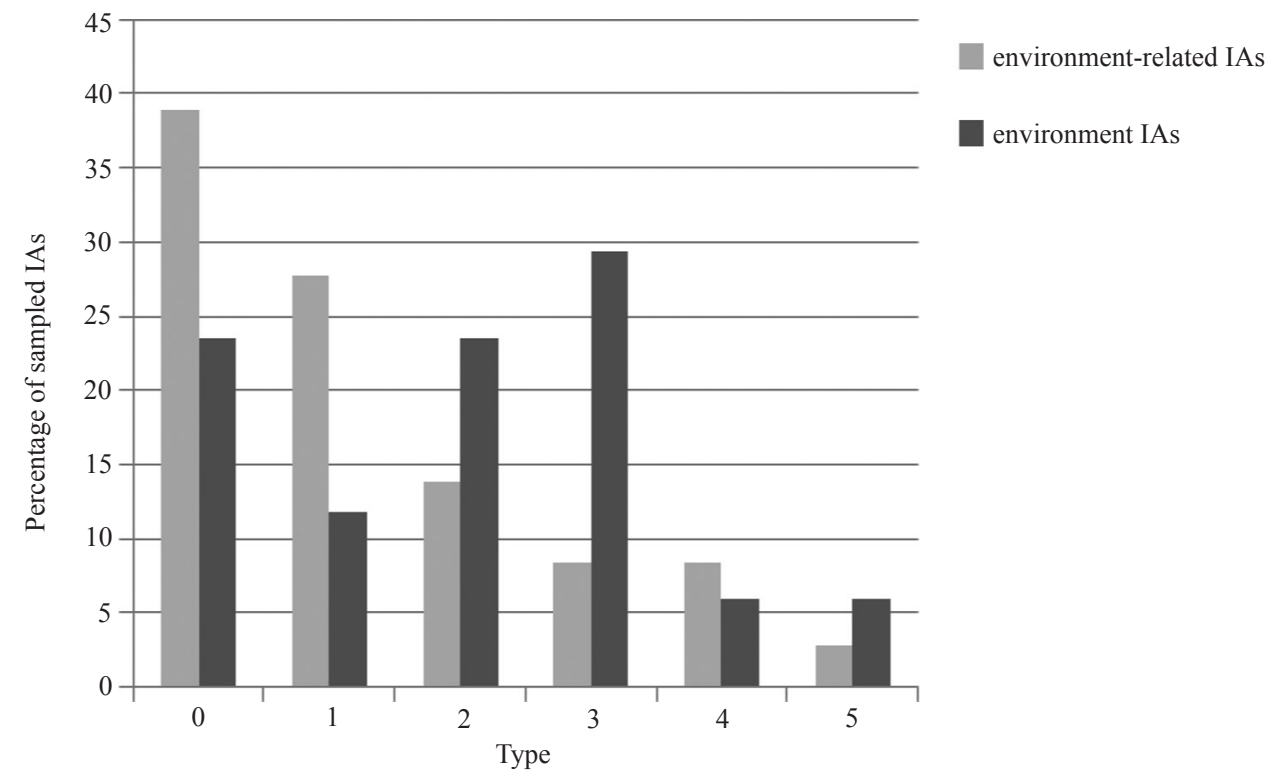

Figure 1. Percentage of sampled impact assessments (IAs) with different types of ecosystem services framing: environment versus environment-related policies.

Crucially, an explicit ecosystems framing (ie, types 4 or 5) was found in only about $12 \%$ of both environment and environment-related policy cases. The most common areas are climate change, energy, and nature conservation. Figure 2 presents the same data from a departmental rather than policy-type perspective. It distinguishes between IAs from the environment ministry (twenty-four cases) and those from other departments (fifty-one cases). This illustrates the spread of the ESA beyond its origins. An explicit ESA framing was found in around $20 \%$ of environment-ministry-led IAs. This seems surprisingly low, given Defra is the lead department.

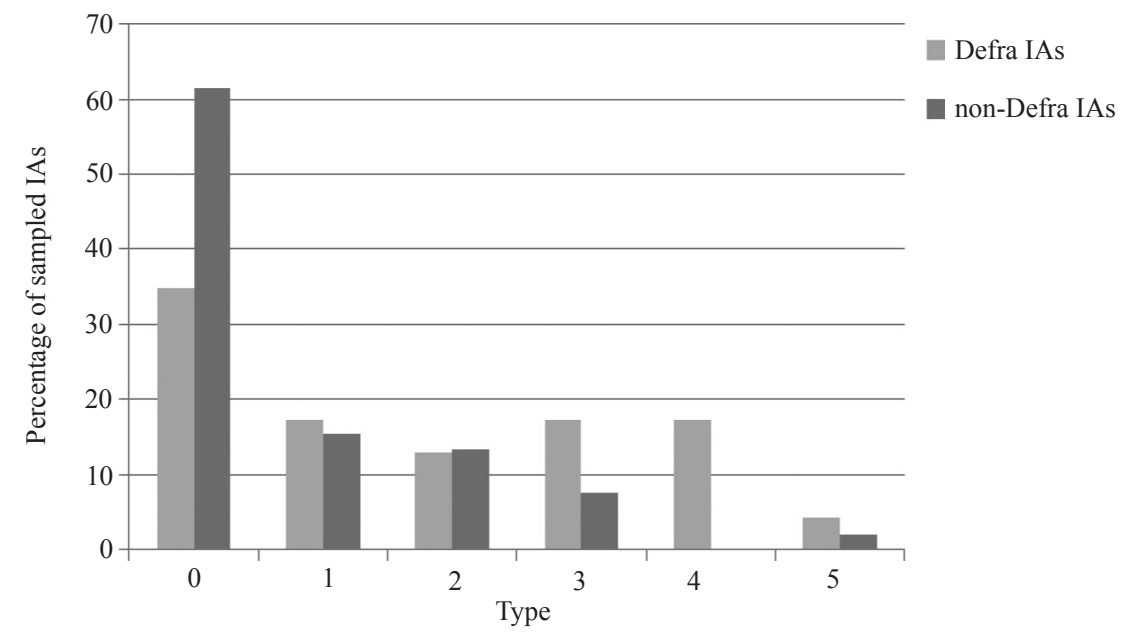

Note: Defra = Department for Environment, Food and Rural Affairs.

Figure 2. Percentage of sampled impact assessments (IAs) with different types of ecosystem services framing: Defra versus non-Defra IAs. 
While an IA may be framed around an ESA or the environment, this does not necessarily mean that the analysis of policy options therein will pick up on these issues in a meaningful way. Figures 3 and 4 show the degree of an ESA evident in the IAs' assessment of the impacts of policies.

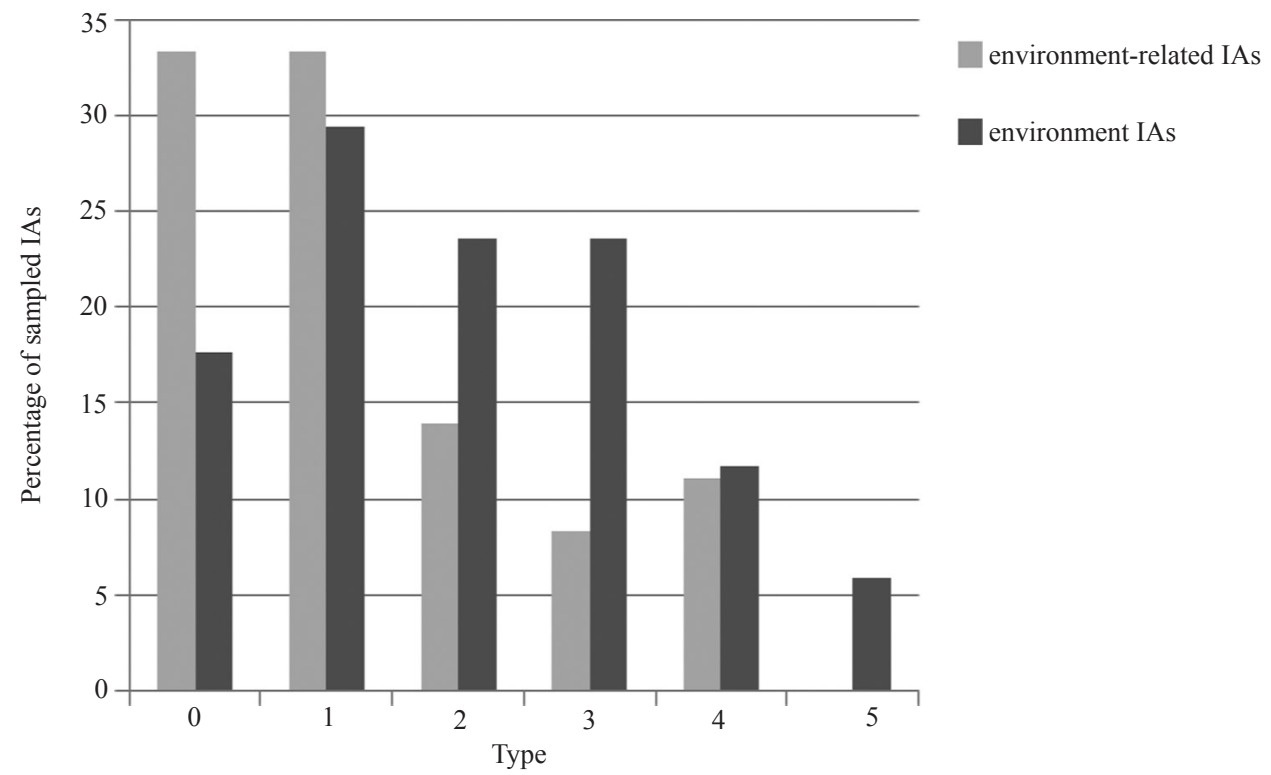

Figure 3. Percentage of sampled impact assessments (IAs) with impact analysis framed to different degrees around an ecosystem services approach: environment versus environment-related policies.

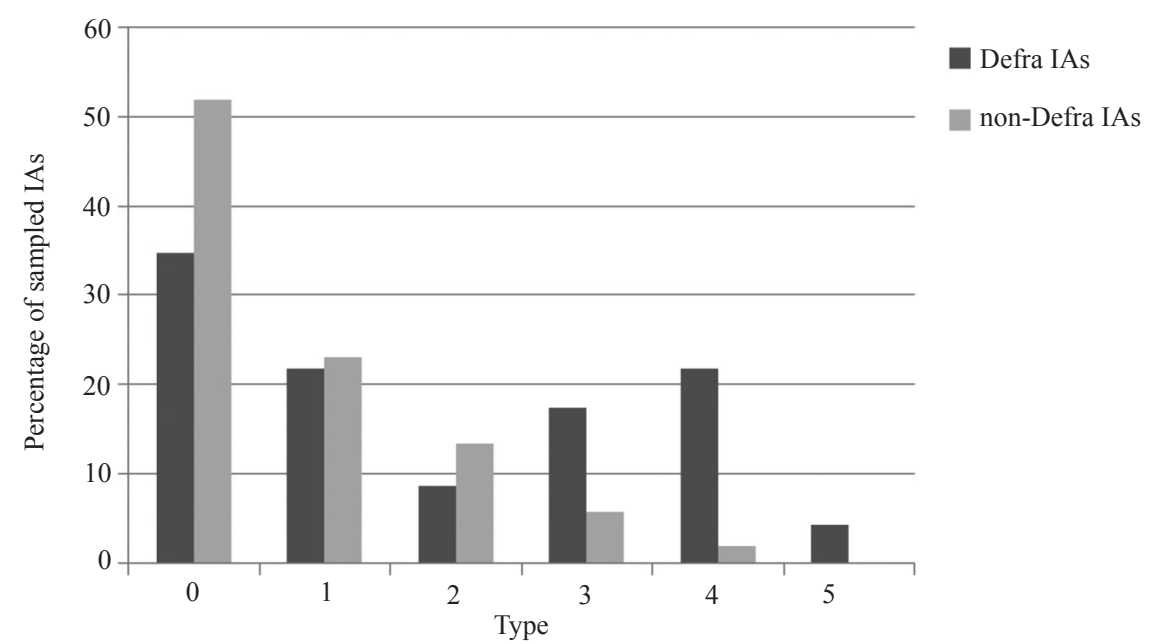

Note: Defra $=$ Department for Environment, Food and Rural Affairs.

Figure 4. Percentage of sampled impact assessments (IAs) with impact analysis framed to different degrees around ecosystem services apprach: Defra versus non-Defra IAs.

About $10 \%$ of environment-related IAs and about $18 \%$ of environment IAs showed evidence of an ESA in the assessment of impacts. These were often the same policy cases as those showing a strong ESA framing. A larger number of IAs were identified that had a strong environmental framing and/or impacts analysis without explicitly mentioning an ESA (ie, type 3): about $25-30 \%$ of environment policy IAs and $8 \%$ of environment-related ones (see figures 1 and 3 ).

We examined in more detail the approach taken in those IAs which had a greater degree of environmental and/or ESA framing, or analysis of impacts - that is, explicitly mentioning 
an ESA or employing a strongly integrated environmental analysis. These are the cases that were classified as types 3, 4, and 5. Fourteen IAs out of the total seventy-five came under this category. Figure 5 illustrates the different elements of an ESA that were most prominent among the IAs in this subsample. It classifies each IA's consideration of the separate elements into one of the above types. Of the results from this analysis, only types 3, 4, and 5 are presented here. Regulating services appears to garner the most attention, with all the subsample of IAs assessing this element to some extent. This compares with the lower profile of cultural services, even among those IAs that are framed around an ESA.

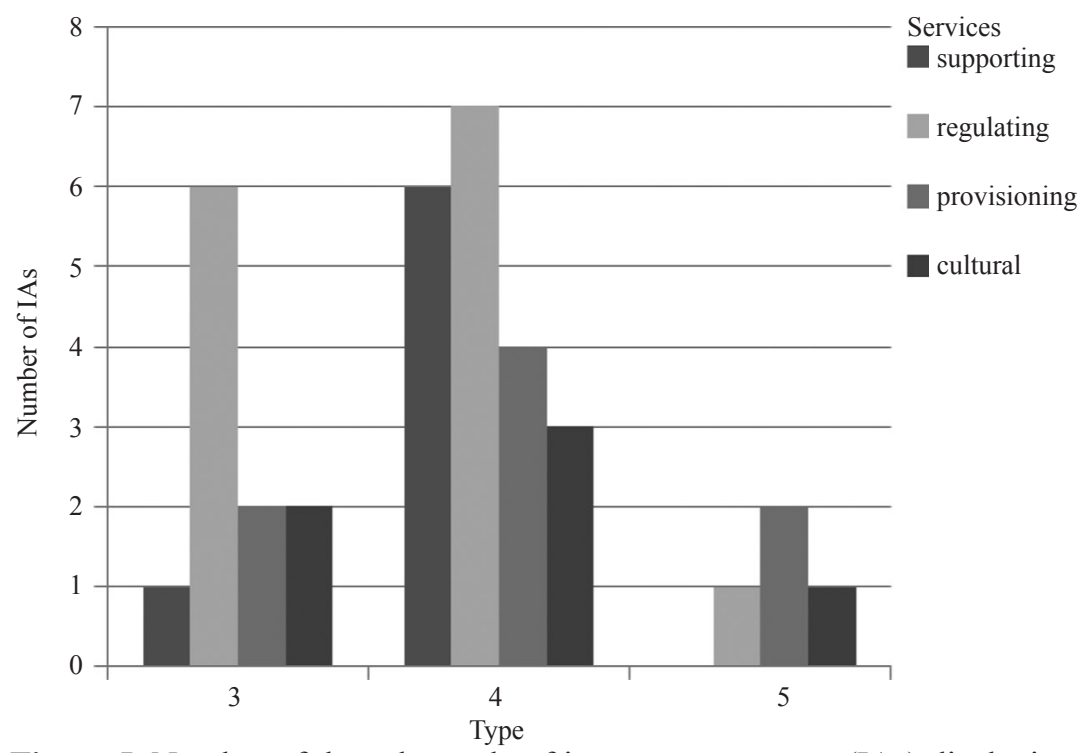

Figure 5. Number of the subsample of impact assessments (IAs) displaying different elements of an ecosystem services approach.

Appraisal processes are typically characterised by the use of analytical tools ${ }^{(1)}$ — such as monetary assessment, modelling, foresight, and participatory tools - to order, process, and generate (new) knowledge (Nilsson et al, 2008). Indeed, the Green Book (HM Treasury, 2012) advocates the use of complex analytical tools and approaches like cost-benefit analysis. Examining the use of different types of tools in IAs gives a particular indication of the level of analysis - remembering that an IA with a strong ESA is likely to employ a wider range of analytical tools and more detailed and integrated analysis.

The seventy-five sampled IAs were examined for the types of tools used to process and generate knowledge. Fully $95 \%$ of the cases showed some form of monetary assessment, including monetary costs and benefits of the policy impacts. Of the cases, $17 \%$ showed use of more sophisticated tools like life-cycle analysis or computer modelling. This represents a significant increase in the use of such tools, compared with that found by previous studies [see Turnpenny et al (2008) and especially Russel and Turnpenny (2009)].

\subsection{Change over time}

While an ESA has been developing for several years, it was formally adopted in the UK only since the NEA and the publication of the Natural Environment White Paper in June 2011. The extent to which this apparently significant adoption appeared in the evidence of embedding

(1) "[A]n analytical technique, scheme, device or operation (including those developed in the fields of economics, mathematics, statistics, operations research and systems dynamics) ... which can potentially be used to provide decision-makers with advice on any of the inter-linked tasks of policy formulation" (based on Jenkins-Smith, 1990, page 11). 
of an ESA in appraisal reports was examined. Within the sample of seventy-five IAs, twenty five date from after June 2011.

Table 1 shows the average score assigned to the IAs in each year. A higher average score indicates that the average IA considers ecosystem knowledge more strongly. While the average score increased in 2011, this was from a rather low value the year before, and it fell back again in 2012, providing no evidence of an immediate increase in the embedding of ESA within the average IA. However, of the six IAs that were classified as types 4 or 5 on framing and/or impacts, five were published around the time of, or just after, the white paper. This may be coincidence, since the time scales of policy development, IA publication, and framing legislation are often at odds, but it is worthy of further investigation.

Table 1. Average impact assessment (IA) type score by year.

\begin{tabular}{ll}
\hline Year & Average type score across all IAs \\
\hline 2008 & 2.6 \\
2009 & 2.3 \\
2010 & 1.7 \\
2011 & 2.7 \\
2012 & 1.3 \\
\hline
\end{tabular}

\section{Understanding and explaining knowledge utilisation in appraisal}

\subsection{To what extent does the ESA appear in UK policy appraisal documents?}

While an ESA first captured the attention of policy makers with the publication of the MEA in 2003, conceptual modes of knowledge utilisation (Sabatier, 1998; Weiss, 1979) suggest that knowledge impacts may not be immediate but can occur over longer time periods as a critical weight of evidence builds up. An explicit ESA framing in around $20 \%$ of Defraled IAs may hence, rather than being surprisingly low, simply be caused by it being too early to observe an ESA's widespread embedding. An ESA may appear first as a simple acknowledgement of its existence, and perhaps a rudimentary framing of the problem with ESA language - before being used subsequently in more detail to generate instrumental results. The observation that more environment policy IAs had a strong environmental framing and/or impacts analysis without explicitly mentioning an ESA may be consistent with this. As suggested above, because the UK has been appraising policy for environmental impacts since the 1990s (Russel and Jordan, 2007), it is perhaps not surprising that this has been more readily picked up than the more recent and narrow concept of an ESA. Indeed, the concept of sustainable development and environmental protection has become common language amongst UK policy makers, albeit not leading to what many critics would call sustainable outcomes (Russel, 2007). Within this environmental framing, there also appear elements not too dissimilar to an ESA, including an integrated approach, and assessment of the impact on a number of different ecological services such as regulating, provisioning, and cultural services with some attempt at monetisation. However, they are not necessarily termed this way in the impact assessments; for example, impacts on climate change may be considered but not framed in terms of a regulating service impact. Thus, although IAs may not be framed with the language of an ESA, they nonetheless consider many elements of it. However, regulating services appear to garner the most attention, with a lower profile for cultural services regardless of the name given to these. It appears that the 'least environmental' aspects of an ESA still appear less frequently than the more explicit natural processes, nature conservation, and food and fuel provision.

Another element of diffusion (or lack thereof) is a disconnect in some cases between analysis and outputs. For example, in the case of transferring the functions of British 
Waterways to the charitable sector, there is a strong ESA framing, but this is somewhat disconnected from the policy outputs, which do not necessarily follow from an ESA (the decision on the source of the funding being separate from the benefits the canal ecosystems bring). In some respects, this refers to what Rich (1997) would call 'utility', where the appraiser sees that the ESA could have value but without identifying how in relation to the policy problem. On the other hand, this may be evidence of a strong disconnect between understanding the implications of a policy impact and a policy going ahead regardless. As with all areas of policy making, trade-offs have to be made (Russel and Turnpenny, 2009), meaning that while a policy maker may understand the ecological implications of policy, other priorities may be driving the policy. Existing literature on policy appraisal suggests that these priorities are shaped politically outside of the appraisal process, through actions such as lobbying, ministerial discretion, and interdepartment negotiations (Russel and Jordan, 2007; Turnpenny et al, 2008).

\subsection{What issues surround ESA's embedding (or not) in policy appraisal?}

Many of the same sorts of issues surrounding embedding any form of environmental knowledge into appraisal appear in the case of an ESA. In some type-4 cases (for example, the 'National Planning Policy Framework' and 'Planning for a Natural and Healthy Environment' cases), an IA may acknowledge that the policy issue at hand has strong implications for ecosystems, but does not actually analyse the impacts of the proposed policy options. It may be that the ecological relevance of the policy is so obvious that it was felt unnecessary to conduct a fuller analysis. The difficulties and ethical dilemmas behind measuring ecological impacts and assessing their costs and benefits, including scientific uncertainty and controversies about monetising environmental costs and benefits, are covered extensively in the existing literature; past research has suggested these factors might contribute to weak analysis of environmental and by extension ecological impacts in policy appraisal (eg, Pearce, 1998; Russel and Jordan, 2007).

Though many examples were found where an ESA has not been taken to analyse impacts, this does not necessarily mean that the assessment is 'bad'. For example, in the twenty-two IAs sampled that were classified as from 'nonenvironment' policy fields, all were classed as Type 0 for an ESA framing, and 86\% were type 0 for an ESA approach to impact analysis, with just a few cases which mention environment in passing. But as Rich (1997, page 12) observes, it "may be fully rational to ignore information or to actively reject it" (also see Dunlop, 2014). For example, in the case of an IA on product placement in visual media ('Legislation to implement the European Audiovisual Media Services Directive: Product Placement on Television'), the ecological impact of the policy is so negligible that not taking an ESA appears logical. Moreover, a similar case can be made for simple policy amendments where impacts are minimal. These are clear examples where the appraiser has not sought out ecological knowledge as it is clearly not relevant to the issue at hand. As Dunlop (2014) notes, this is not necessarily a case of nonuse but may be a form of rejection. However, the not insignificant number of environment and environment-related IAs that did not analyse environmental impacts at all (18\% and 33\%, respectively - see figure 3$)$ are more interesting. Embedding of an ESA to even a minimal extent might be expected in these cases, but it appears to be missing. Understanding the reasons behind this, and the associated capacities and constraints, is therefore crucial.

On the surface, many of the observations seen in the sampled appraisals appear to conform to the notion of justificatory use. There was ample evidence that, despite some signs of at least a strong environmental framing and attempts at more sophisticated tool use to analyse impacts, many assessments appeared to use tools only to examine preselected policy proposals: for example, cases where only two options were considered (do nothing versus 
do something), or only one option was analysed, or policy set by EU was simply framed as 'to implement or not' rather than exploring implementation options. Related to these are cases whose premise is environment or sustainable development, but where the IAs focus on one very specific aspect such as data availability, infrastructure siting, or legal procedures, ${ }^{(2)}$ which can explain some of why only around $20 \%$ of environment ministry IAs explicitly show an ESA. This situation is not unique to an ESA, however. Other empirical studies have observed that some appraisals tend to focus on fairly narrow implementation options once the policy direction has already been formulated, and hence have limited impact on strategic policy direction (Dunlop et al, 2012; Russel and Jordan, 2007; Russel and Turnpenny, 2009).

A requirement to consider integration across environmental, economic, and social effects is exemplified by the fact that official guidance says that all IAs must at least consider these impacts. While the response is often to simply say there are 'no impacts', this does at least make policy makers think more widely than the often narrow remit of the policy appraisal. However, in the current sample there was almost no evidence of attempts at valuing of ecosystem services, even among the small subset of IAs that explicitly examined ESA impacts.

\section{Conclusions and new directions for analysis and policy}

Policy appraisal has been identified as a crucial venue to embed an ESA within policy making. In many ways it is an old solution to a much older problem: how to 'green' policy making. However, there are, to date, very few empirical analyses of how far this hope is actually being realised. Without such analyses, policy pronouncements run the risk of running ahead of everyday policy practices and/or being misconceived. This paper has addressed this important policy gap by exploring the embedding of ecological knowledge in the venue of policy-level appraisal in the UK, a world-leading advocate of the ESA.

The findings reveal that while UK authorities can draw on extensive experience, there are still significant obstacles standing in the way of the systematic embedding of an ESA in practice. Relatively few appraisals (about $10 \%$ of environment-related IAs, and about $18 \%$ of environment IAs) exhibited evidence of an ESA in their assessment of impacts. While an IA may acknowledge that the policy issue at hand has strong implications for ecosystems, it may not actually analyse the impacts, and/or it may be somewhat disconnected from the policy outputs. Even among those that do consider an ESA, it appears that the 'least environmental' aspects of an ESA still appear less frequently than the more explicit natural processes, such as nature conservation, and food and fuel provision. New ideas are often slow to diffuse and spread, at least at first, because of institutional inertia, preexisting policy constraints, the time taken for new coalitions of interests to be formed around the new ideas, and the potentially significant shifts in intellectual changes required from different policy actors (Owens, 2012; Sabatier, 1988). The evidence from this paper is that an ESA is indeed taking time to diffuse, even within the UK environment ministry.

Earlier, it was suggested that appraisal was 'different' from other types of knowledge utilisation venues as it forces decision makers to seek and synthesise knowledge. However, the empirical findings suggest that appraisal exhibits many of the patterns of knowledge use observed in other nonappraisal venues (see Cowell and Lennon, 2014; Haines-Young and Potschin, 2014; MacKenzie et al, 2014; Waylen and Young, 2014), including slow diffusion

${ }^{(2)}$ As seen, for example, in the following cases: 'Proposal to Consolidate and Amend the Town and Country (Environmental Impact Assessment) (England and Wales) Regulations 1999'; 'Fairer and Better Environmental Enforcement proposals'; 'Amendments to Planning Policy Statement 25: Development and Flood Risk'; 'Making better use of Energy Performance Data'; 'The Sea Fishing (Illegal, Unreported and Unregulated Fishing) Order 2009'; and 'Plant Protection Products: Enforcement Regulations and Fees Regulations'. 
of ideas and the limitations of a linear-rational model of knowledge use. This is not to say that policy appraisal is unsuitable for embedding an ESA - see, for instance, the discussion on the conceptual use of knowledge — but it does raise important areas for future research, discussed below.

Crucially, it is important to bear in mind that some IAs revealed a stronger environmental or sustainable development framing without explicitly mentioning an ESA: about 25-30\% of environment IAs and $8 \%$ of environment-related cases. This was particularly noticeable around the requirement to consider environmental, sustainable development and greenhouse gas impacts of all policy proposals. This requirement may not produce much (or any) analysis or influence on the policy output, but it requires officials to at least think about the issues; they are not completely alien concepts. The impacts of such requirements are not trivial. Consider, for example, the change in quality of UK IAs over time: there was a significant increase in the sophistication of analysis present in the IAs as a whole, compared with that found by past studies. Crucially, monetary assessment is now strongly promoted in IA guidance, and it actually gets carried out in almost all cases, and reasonably comprehensively, although there is a tendency still to monetise economic impacts rather than environmental ones. The point is that an official obligation to carry out a certain type of analysis is an important factor in its uptake. On this point, there is now supplementary guidance on ecosystems in the UK Treasury's Green Book, an institution normally very resistant to change. It remains to be seen what impact this will have on the embedding of an ESA in IAs. There are also questions about whether the strong promotion of valuation in the NEA (and Green Book) is likely to enhance or hinder the embedding of ecological knowledge in decision making.

Nevertheless, there remains a relatively large number of IAs on environmental policy which report very little analysis of any sort: a finding which again chimes with previous studies. Particularly, the narrow remit of IA still appears to affect ability to carry out extensive new analysis or policy reframing. To be clear, the absence of an ESA is not necessarily a problem to be rectified - it could simply be that the concept is of minimal relevance to the policy at hand and therefore knowledge is not deemed useful and is rejected (Dunlop, 2014). But it will be interesting to examine cases where integration of an ESA might be more expected but it is not happening, for whatever reason, and also the cases where there is stronger evidence of an ESA - to see why and how the concept has been taken up, and with what results.

Future research on better understanding the influence of an ESA on policy outputs and outcomes will complement this paper's findings on the appearance (or not) of an ESA in policy appraisal activities. While looking for ESA knowledge within appraisal tells us something about how it is prioritised in the policy-making process, it tells us little about the factors that shaped the ultimate policy decision. It may be, for example, that an appraisal had a strong ecosystems framing but had little impact on the final policy decision - or vice versa. Future research could help to tease out the influences that did not result in action (eg, information received, read, and rejected). A further strand of research could focus on the influences on the ESA framing itself, and the likelihood that such a framing will form the basis of policymaking activity in the first place. For example, the influence of political party, degree of politicisation of a policy problem, and the problem structure may all be critical factors which will ultimately dictate whether an ESA and associated knowledge is picked up in appraisal processes.

Acknowledgements. This work was partly funded through the 'BRIDGE' (Bridging the gap between supply and demand for valuation evidence) project under the Valuing Nature Network funded by the UK Natural Environment Research Council and Defra. We particularly thank participants at the BRIDGE Decisions Workshop, 3-4 May 2012, for their constructive comments. 


\section{References}

Adelle C, Jordan A, Turnpenny J R, 2012, "Proceeding in parallel or drifting apart? A systematic review of policy appraisal research and practices" Environment and Planning C: Government and Policy 30 401-415

Barker A, 1993, "Patterns of decision advice processes: a review of types and a commentary on some recent British practices", in Advising West European Governments: Inquiries, Expertise and Public Policy Eds B G Peters, A Barker (Edinburgh University Press, Edinburgh) pp 20-36

Billé R, Laurans Y, Mermet L, Pirard R, Rankovic A, 2012, "Valuation without action? On the use of economic valuations of ecosystem services", IDDRI Policy Brief No. 07/12, April, Insitut du développement durable et des relations internationales, Paris

CEC, 2009 Impact Assessment Guidance SEC(2009)92 (Commission of the European Communities, Brussels)

CEC, 2012, "Assessing and strengthening the science and EU environment policy interface", report by Milieu Ltd and Collingwood Environmental Planning Ltd for DG Environment of the European Commission under Contract No. 07.0307/2010/581217/SER/F4, Commission of the European Communities, Brussels

Coleby A M, van der Horst D, Hubacek K, Goodier C, Burgess, P J, Graves A, Lord R, Howard D, 2012, "Environmental Impact Assessment, ecosystems services and the case of energy crops in England" Journal of Environmental Planning and Management 55 369-385

Cowell R, Lennon M, 2014, "The utilisation of environmental knowledge in land-use planning: drawing lessons for an ecosystem services approach" Environment and Planning C: Government and Policy 32 263-282

Craik N, Doelle M, Gale F, 2012, "Governing information: a three-dimensional analysis of environmental assessment" Public Administration 90 19-36

DoE, 1990 This Common Inheritance Department of the Environment (HMSO, London)

DoE, 1991 Policy Appraisal and the Environment Department of the Environment (HMSO, London)

Dunlop C A, 2014, "The possible experts: how epistemic communities negotiate barriers to knowledge use in ecosystems services policy" Environment and Planning C: Government and Policy 32 208-228

Dunlop C A, Russel D, 2012, "Watching the detectives: explaining the role of regulators in implementing sustainable development" Public Management Review 14(5) 1-24

Dunlop C A, Maggetti M, Radaelli C M, Russel D, 2012, "The many uses of regulatory impact assessment: a meta-analysis of EU and UK cases" Regulation and Governance 6 23-45

Foster J (Ed.), 1997 Valuing Nature? Economics, Ethics and Environment (Routledge, London)

Haigh N, 2008 Manual of Environmental Policy (Maney, Leeds)

Haines-Young R, Potschin M, 2009, "Methodologies for defining and assessing ecosystem services", CEM Report 14, final report to Joint Nature Conservation Committee, August, Centre for Environmental Management, University of Nottingham, Nottingham

Haines-Young R, Potschin M, 2014, "The ecosystem approach as a framework for knowledge utilisation" Environment and Planning C: Government and Policy 32 301-319

Hanley N, 2001, "Cost-benefit analysis and environmental policymaking" Environment and Planning C: Government and Policy 19 103-118

Helming K, Diehl K, Geneletti D, Wiggering H, 2013, "Mainstreaming ecosystem services in European policy impact assessment" Environmental Impact Assessment Review 40 82-87

Hertin J, Turnpenny J, Jordan A, Nilsson M, Russel D, Nykvist B, 2009, "Rationalising the policy mess? Ex ante assessment and the utilisation of knowledge in the policy process" Environment and Planning A 41 1185-1200

HM Government, 2011 The Natural Choice: Securing the Value of Nature Cm 8082 (The Stationery Office, London)

HM Treasury, 2012 The Green Book: Appraisal and Evaluation in Central Government (The Stationery Office, London)

Hockley N, 2014, "The use and influence of cost-benefit analysis: a venue for integrating ecosystem knowledge in decision making" Environment and Planning C: Government and Policy 32 283-300 
Howlett M, Craft J, 2012, "Policy advisory systems and evidence-based policy: the location and content of evidentiary policy advice", paper presented at the Evolution of Evidence-Based Policy Making in Canada workshop, 8-9 August, School of Public Policy and Governance, University of Toronto, ON; available from J Turnpenny

Jenkins-Smith H, 1990 Democratic Politics and Policy Analysis (Brooks/Cole, Belmont, CA)

Jordan A, Russel D, 2014, "Embedding an ecosystems services approach? The utilisation of ecological knowledge in decision making" Environment and Planning C: Government and Policy 32 192-207

Jordan A, Schout A, 2006 The Coordination of the European Union (Oxford University Press, Oxford)

MEA, 2003 Ecosystems and Human Well-being: A Framework for Assessment Millennium Ecosystem Assessment (Island Press, Washington, DC)

Nilsson M, Jordan A, Turnpenny J, Hertin J, Nykvist B, Russel D, 2008, “The use and non-use of policy appraisal in public policy making: an analysis of three European countries and the European Union" Policy Sciences 41 335-355

Norgaard R, 2010, "Ecosystem services: from eye-opening metaphor to complexity blinder" Ecological Economics 69 1219-1227

Owens S, 2012, "Experts and the Environment-The UK Royal Commission on Environmental Pollution 1970-2011" Journal of Environmental Law 24 1-22

Owens S, Rayner T, Bina O, 2004, "New agendas for appraisal: reflections on theory, practice, and research" Environment and Planning A 36 1943-1959

McKenzie E, Posner S, Tillmann P, Bernhardt J R, Howard K, Rosenthal A, 2014, “Understanding the use of ecosystem service knowledge in decision making: lessons from international experiences of spatial planning" Environment and Planning C: Government and Policy 32 $320-340$

Pearce D, 1998, "Cost benefit analysis and environmental policy" Oxford Review of Economic Policy 14(4) 84-100

Pearce D W, 2004, "Does European Union policy pass a cost benefit test?" World Economics $5115-137$

Radaelli C M, 2005, "Diffusion without convergence: how political context shapes the adoption of regulatory impact assessment" Journal of European Public Policy 12 924-943

Radaelli C, 2007, "Does regulatory impact assessment make institutions think?", paper presented at Governing the European Union: Policy Instruments in a Multi-Level Polity seminar, 21-22 June, Paris; copy available from J Turnpenny

Rich R F, 1997, "Measuring knowledge utilization: processes and outcomes" Knowledge and Policy 10(3) 11-24

Russel D, 2007, “The United Kingdom's sustainable development strategies: leading the way or flattering to deceive?" European Environment 17 189-200

Russel D, Jordan A, 2007, "Gearing-up governance for sustainable development: patterns of policy appraisal in UK central government" Journal of Environmental Planning and Management $501-21$

Russel D, Jordan A, 2009, “Joining up or pulling apart? The use of appraisal to coordinate policy making for sustainable development" Environment and Planning A 41 1201-1216

Russel D, Turnpenny J, 2009, "The politics of sustainable development in UK government: what role for integrated policy appraisal?" Environment and Planning C: Government and Policy 27 340-354

Russel D, Turnpenny J, Rayner T, 2013, "Reining in the executive? Delegation, evidence and parliamentary influence on environmental public policy" Environment and Planning C: Government and Policy 31 619-632

Sabatier P, 1988, "An advocacy coalition framework of policy change and the role of policy-oriented learning therein" Policy Sciences 21 129-168

Sabatier P A, 1998 "The advocacy coalition framework: revisions and relevance for Europe" Journal of Public Policy 5 98-130

Turner R K, 2007, "Limits to CBA in UK and European environmental policy: retrospects and future prospects" Environmental Resource Economics 37 253-269 
Turner R K, Paavola J, Cooper P, Farber S, Jessamy V, Georgiou S, 2003, "Valuing nature: lessons learned and future research directions" Ecological Economics 46 493-510

Turnpenny J, Nilsson M, Russel D, Jordan A, Hertin J, Nykvist B, 2008, "Why is integrating policy assessment so hard?" Journal of Environmental Planning and Management 51 759-775

Turnpenny J, Radaelli C, Jordan A, Jacob K, 2009, "The policy and politics of policy appraisal: emerging trends and new directions" Journal of European Public Policy 16 640-653

UK NEA, 2011a The UK National Ecosystem Assessment: Technical Report United Nations Environment Programme and World Conservation Monitoring Centre, Cambridge

UK NEA, 2011b The UK National Ecosystem Assessment: Synthesis of the Key Findings United Nations Environment Programme and World Conservation Monitoring Centre, Cambridge

Waylen K, Young J, 2014, "Expectations and experiences of diverse forms of knowledge use: the case of the UK National Ecosystem Assessment" Environment and Planning C: Government and Policy 32 229-246

Weiss C, 1979 "The many meanings of research utilization" Public Administration Review 39 426-431

Wilkinson D, Fergusson M, Bowyer C, Brown J, Ladefoged A, Monkhouse C, Zdanowicz A, 2004, "Sustainable development in the European Commission's Integrated Impact Assessments for 2003: final report", Institute for European Environmental Policy, London

\section{Appendix}

Table A1. Summary of impact assessments (IAs) analysed.

\begin{tabular}{lllll}
\hline Department & $\begin{array}{l}\text { Total number } \\
\text { of IAs } \\
\text { sampled }\end{array}$ & $\begin{array}{l}\text { Environment } \\
\text { policy cases }\end{array}$ & $\begin{array}{l}\text { Environment- } \\
\text { related policy } \\
\text { cases }\end{array}$ & $\begin{array}{l}\text { Nonenvironment } \\
\text { policy cases }\end{array}$ \\
\hline Cabinet Office & 1 & 0 & 0 & 1 \\
$\begin{array}{l}\text { Department for Business, } \\
\text { Innovation and Skills }\end{array}$ & 4 & 0 & 0 & 4 \\
$\begin{array}{l}\text { Department for Communities } \\
\text { and Local Government }\end{array}$ & 15 & 2 & 9 & 4 \\
$\begin{array}{l}\text { Department for Culture, Media } \\
\text { and Sport }\end{array}$ & 2 & 0 & 0 & 2 \\
$\begin{array}{l}\text { Department of Energy and } \\
\text { Climate Change }\end{array}$ & 5 & 1 & 4 & 0 \\
$\begin{array}{l}\text { Department for Environment, } \\
\text { Food and Rural Affairs }\end{array}$ & 24 & 11 & 13 & 0 \\
$\begin{array}{l}\text { Department for Education } \\
\text { Department for Transport }\end{array}$ & 4 & 0 & 0 & 4 \\
$\begin{array}{l}\text { Department of Health } \\
\text { Department for Work and }\end{array}$ & 3 & 2 & 10 & 0 \\
Pensions & 1 & 0 & 0 & 3 \\
Forestry Commission & 1 & 0 & 0 & 1 \\
HM Treasury & 1 & 1 & 0 & 0 \\
Home Office & 1 & 0 & 0 & 1 \\
Ministry of Justice & 1 & 0 & 0 & 1 \\
\hline
\end{tabular}

